\title{
Analisis Persedian Bahan Baku, Reorder Point dan Safety Stock Bahan Baku ADC-12
}

\author{
Hazimah $^{1 *}$, Yongki Antoni Sukanto ${ }^{2}$, Nurlinda Ayu Triwuri ${ }^{3}$ \\ ${ }^{1,2}$ Program Studi Teknik Industri Universitas Putera Batam \\ ${ }^{3}$ Politeknik Negeri Cilacap, J1. Dr. Soetomo, No.1 Sidakaya Cilacap \\ *Correspondence email: hazimahima1987@gmalil.com; nurlindaayutriwuri@pnc.ac.id
}

\begin{abstract}
Abstrak. Proses produksi yang dilakukan sangat bergantung dengan ketersediaan bahan baku. Perhitungan persediaan bahan baku yang optimal sangat dibutuhkan agar perusahaan terhindar dari permasalahan kekurangan atau kelebihan stock bahan baku. Penelitian ini bertujuan untuk menentukan kuantitas persediaan bahan baku, safety stock, dan reorder point terhadap bahan baku ADC-12. Penelitian ini menggunakan pendekatan deskriptif kuantitatif.Sumber data diperoleh secara langsung dari perusahaan.Analisis data yang digunakan menggunakan metode Economic Order Quantity.Berdasarkan penelitian dan hasil perhitungan yang telah dilakukan, jika perusahaan menggunakan metode $E O Q$ kuantitas persediaan bahan baku yaitu sebanyak $80.861 \mathrm{~kg}$, kuantitas persediaan pengaman yaitu sebanyak $2.768 \mathrm{~kg}$ dengan titik pemesanan kembali $(R O P)$ sebanyak $14.038 \mathrm{~kg}$.
\end{abstract}

Kata kunci: Bahan baku; Economic Order Quantity (EOQ); Total Biaya Persediaan; Safety stock dan Reorder point

\begin{abstract}
The production process is very dependent on the availability of raw materials. An optimal calculation of raw material inventory is needed so that the company avoids the problem of lack or over stock of raw materials. This research aims to find out the quantity of raw material inventory, safety stock, and reorder point for ADC-12 raw materials.. This research uses a quantitative descriptive approach. Data sources obtained directly from the company. Analysis of the data used using the Economic Order Quantity method. Based on research and calculation results that have been done, if the company uses the EOQ method the quantity of raw material inventory is $80,861 \mathrm{~kg}$. The quantity of the safety stock is $2,768 \mathrm{~kg}$ with a reorder point (ROP) of $14,038 \mathrm{~kg}$.
\end{abstract}

Keywords: Raw Material; Economic Order Quantity (EOQ); Total Inventory Cost; Safety Stock, Frequency of Purchase; Reorder Point

\section{PENDAHULUAN}

Pada proses produksi merubah sesuatu yang tidak bernilai atau non value added menjadi bernilai atau value added (Sulaiman \& Nanda, 2015).Dalam industri manufaktur, produksi menjadi hal yang sangat terpenting. Jika dalam proses produksi terdapat kendala maka dapat mempengaruhi tingkat produktivitas suatu industry (Fauzi \& Hartono, 2019). Sedangkan, produktivitas merupakan salah satu tolak ukur perusahaan untuk mendapatkan keuntungan sesuai tujuan. Agar tujuan perusahaan dapat tercapai sangat diperlukan strategi yang tepat (Indah \& Maulida, 2018).

Bahan baku merupakan salah satu faktor utama yang dapat mempengaruhi kelancaran dari proses produksi (Amirullah \& Endang, 2016). Dengan demikian perusahaan harus mampu membuat perencanaan yang maksimal dari persediaan bahan baku yang diperlukan untuk menciptakan suatu produk (Björk, K.M, 2012). Perencanaan yang efektif dan efisien mampu membuat perusahaan memperoleh keuntungan. Jika perusahaan melakukan perencanaan dengan tidak tepat maka akan timbul pemborosan terhadap biaya yang dikeluarkan (Palupi et al, 2018). Persediaan bahan baku yang melewati dari kebutuhan perusahaan mengakibatkan biaya penyimpanan yang cukup besar. Sebaliknya, jika perusahaan melakukan pengurangan persediaan bahan baku maka perusahaan akan menghadapi situasi stock out (Lahu et al., 2017).

Adanya persediaan dalam sistem memiliki satu tujuan tertentu. Alasan terutamanya yaitu adanya bahan baku tersebut tidak bisa disediakan disaat bahan baku tersebut dibutuhkan, oleh karena itu untuk menjamin ketersedian bahan baku tersebut perlu adanya persediaan yang baik digunakan pada saat dibutuhkan. Dengan adanya persediaan akan berdampak berupa resiko-resiko tertentu yang harus ditanggung oleh perusahaan akibat dari persediaan tersebut, persediaan yang disimpan oleh perusahaan akan menimbulkan biaya penyimpanan, selain itu juga perusahaan akan menanggung biaya-biaya yang disebabkan dengan adanya persediaan (Sofiyanurriyanti. S, 2017). Bahan baku yang terlalu lama disimpan tetapi tidak digunakan juga akan menghilangkan kualitas dari bahan baku itu sendiri(Turnip \& Kartikasari, 2017).

Untuk menghindari biaya besar yang ditimbulkan dari persediaan bahan baku, dapat digunakan beberapa metode diantaranya Economic Order Quantity (EOQ). Economic Order Quantity adalah perhitungan yang digunakan untuk menentukan kuantitas pesanan perusahaan, metode ini bisa digunakan dalam mengetahui kuantitas bahan baku yang ekonomis pada setiap kali pemesan sehingga dapat meminimalkan biaya persediaan. Persediaan akan terus dilakukan secara 
continue demi keberlangsungan dari proses produksi perusahaan dan sampai pada saat proses pemesanan lagi sehingga datangnya material yang dipesan sesuai dengan keinginan atau tepat waktu (safety stock). Reorder point adalah waktu yang dibutuhkan perusahaan harus mengadakan pemesanan bahan dasar kembali dalam jangka waktu tertentu, sehingga datangnya pesanan tersebut tepat dengan habisnya bahan baku yang di beli. Dengan begitu ketiga model tersebut sangat diperlukan untuk mengendalikan persediaan dalam sebuah perusahaan (Han, Fajrin, \& Slamet, 2016).

Penelitian ini bertujuan untuk mengetahui safety stock, dan reorder pointterhadap bahan baku ADC-12 di Perusahaan Manufaktur bidang die casting spare part sepeda. Perusahaan ini setiap harinya perusahaan memproduksi spare part sepeda, oleh karena itu diperlukan persediaan bahan baku dalam pengawasan agar tidak terjadinya kekurangan maupun kelebihan bahan baku. Perhitungan persediaan bahan baku dilakukan oleh divisi store. Perhitungan dilakukan perusahaan secara berkala tiap bulannya. Bahan baku yang digunakan dalam perusahaan terdiri dari berbagai jenis alumunium diantaranya ADC5, ADC6, ADC10 dan ADC12.

Jenis alumunium yang digunakan selalu berbeda berdasarkan produk yang akan di produksi. Dalam penelitian ini menganalisis perhitungan safety stock dan reorder point bahan baku ADC12, dikarenakan kuantitas bahan baku ADC12 ini paling banyak digunakan oleh Perusahaan.

\section{METODE}

Dalam penelitian ini yang menjadi populasi yaitu data bahan baku ADC12 di PT Three Cast Indonesia dari Januari 2018 sampai dengan Desember 2018. Dalam penelitian ini peneliti menggunakan teknik sampling purposive untuk menentukan sampel, yaitu cara memilih sampel dengan pertimbangan tertentu. Sampel dalam penelitian ini adalah Head Officer divisistore pada PT Three Cast Indonesia.

\section{Perhitungan safety stock}

Dalam melakukan pemesanan bahan baku diperlukan jangka waktu yang bervariasi mulai dalam hitungan jam sampai hitungan bulan. Jangka waktu dari saat memesan sampai bahan baku datang disebut waktu tenggang atau lead time. Lead time sangat dipengaruhi oleh jarak lokasi antara pemasok dan pembeli serta ketersediaan dari bahan baku yang dipesan, maka dari itu safety stock atau stok pengaman sangat diperlukan. Untuk mengetahui jumlah safety stock ADC 12, perhitungandilakukan dengan rumus sebagai berikut:

Safety Stock $=$ SD x Z

$\mathrm{SD}=\sqrt{\frac{\sum(x-y)^{n} 2}{n}}$
Keterangan:

$\mathrm{SD}=$ Standar Deviasi

$\mathrm{Z} \quad=$ Standar penyimpangan

\section{Perhitungan pemesanan kembali / reorder point (ROP)}

Suatu titik dari jumlah persediaan yang ada pada saat dimana pemesanan kembali dilakukan disebut dengan reorder point (ROP). Untuk menghitung nilai dari ROP digunakan rumus berikut:

$\mathrm{ROP}=(\mathrm{U} \times \mathrm{L})+$ safety stock

Keterangan:

$\mathrm{ROP}=$ reorder point

$\mathrm{U} \quad=$ tingkat kebutuhan per periode

$\mathrm{L} \quad=$ lead time

\section{Perhitungan persediaan maksimum (maximum inventory)}

Batas jumlah persediaan paling banyak yang dapat diandalkan oleh perusahaan sangat diperlukan sehingga kuantitas persediaan yang terdapat di dalam gudang tidak melebihi (over stock).Perhitungan batas jumlah persediaan (maximum inventory) menggunakan rumus berikut.

\section{Maximum Inventory $=$ Safety Stock $+E O Q$}

\section{HASIL DAN PEMBAHASAN}

Karakteristik data dalam penelitian ini sangat diperlukan untuk membantu peneliti dalam melakukan perhitungan biaya persediaan yang ada pada Perusahaan.Data yang digunakan yaitu data operasional perusahaan terkait dengan bahan baku ADC-12 yang dijadikan peneliti sebagai obyek penelitian. Data bahan baku ADC-12 merupakan data yang berorinetasi pada proses dan berisi data - data histori perusahaan yang akan dipakai peneliti dalam melakukan perhitungan. Adapun data yang dipakai dalam penelitian ini yaitu sebagai berikut:

Berdasarkan data yang diperoleh, persediaan awal bahan baku ADC-12 untuk periode Januari2018 yaitu sebesar $47.867 \mathrm{~kg}$. Data tersebut dapat dilihat pada Tabel 1 .

Tabel 1. Persediaan awal bahan baku ADC-12 tahun 2018

\begin{tabular}{ccc}
\hline No & Bulan & Bahan baku $(\mathbf{K g})$ \\
\hline 1 & Januari & 47.867 \\
2 & Februari & 43.806 \\
3 & Maret & 22.993 \\
4 & April & 24.395 \\
5 & Mei & 20.395 \\
6 & Juni & 13.175 \\
7 & Juli & 2.155 \\
8 & Agustus & 4.155 \\
9 & September & 22.745 \\
10 & Oktober & 6.977 \\
11 & November & 5.076 \\
12 & Desember & 23.766 \\
& Total & $\mathbf{2 3 7 . 5 0 5}$ \\
\hline
\end{tabular}


Kebutuhan bahan baku ADC-12 di Perusahaan tidak bersifat konstan, dikarenakan sangat bergantung terhadap permintaan produk yang diinginkan oleh konsumen. Jika permintaan akan suatu produk besar, maka ketersediaan bahan baku dari perusahaan harus bisa mencukupi kebutuhan dalam memproduksi produk. Agar bisa mengetahui jumlah dari bahan baku secara efisien dan optimal, maka terlebih dahulu kita harus mengetahui kebutuhan bahan baku perusahaan tiap bulannya. Data kebutuhan bahan baku ADC-12 pada Tahun 2018 dapat dilihat pada Tabel 2.

Tabel 2. Pemakaian aktual bahan baku ADC-12 tahun 2018

\begin{tabular}{ccc}
\hline No & Bulan & Bahan baku $(\mathbf{K g})$ \\
\hline 1 & Januari & 35.000 \\
2 & Februari & 25.000 \\
3 & Maret & 27.000 \\
4 & April & 24.000 \\
5 & Mei & 19.000 \\
6 & Juni & 18.000 \\
7 & Juli & 18.000 \\
8 & Agustus & 19.000 \\
9 & September & 28.000 \\
10 & Oktober & 28.000 \\
11 & November & 11.737 \\
12 & Desember & 37.000 \\
\hline
\end{tabular}

\begin{tabular}{lc}
\hline Total & 289.737 \\
Rata - rata / Bulan & 24.145 \\
Rata - rata / Hari & 929 \\
\hline
\end{tabular}

Berdasarkan tabel di atas dapat dilihat bahwa rata - rata pemakaian aktual dari bahan baku ADC-12 sebesar $24.145 \mathrm{~kg}$. Pemakaian terbesar terjadi pada bulan Desember yaitu sejumlah $37.000 \mathrm{~kg}$. Pemakaian terkecil terjadi di bulan Juni dan Juli yaitu sebesar $18.000 \mathrm{~kg}$, hal ini dikarenakan permintaan konsumen terhadap produk yang menggunakan bahan baku ADC-12 sedikit. Untuk rata - rata pemakaian ADC-12 yaitu sebesar $929 \mathrm{~kg}$. Total pemakaian bahan baku ADC-12 pada Tahun 2018 yaitu sebesar $289.737 \mathrm{~kg}$.

Total pembelian bahan baku ADC-12 pada Tahun 2018 yaitu sebesar $225.407 \mathrm{~kg}$ sebanyak 11 kali dalam satu tahun. Perusahaan melakukan pembelian bahan baku hanya berdasarkan perkiraan, tanpa melakukan perhitungan secara tepat. Pembelian bahan baku paling besar terjadi di bulan November sebesar $30.427 \mathrm{~kg}$ dengan harga beli senilai SGD 109.689. Pembelian terkecil yaitu di bulan Juni yaitu sebesar $6.980 \mathrm{~kg}$ dengan harga beli senilai SGD 25.163. Data pembelian bahan baku ADC-12 tahun 2018 dapat dilihat pada Tabel 3.

Tabel 3. Pembelian bahan baku ADC-12 tahun 2018

\begin{tabular}{|c|c|c|c|}
\hline Bulan & Bahan Baku (kg) & Harga Beli (SGD) & Harga Beli (Rp) \\
\hline Januari & 20 & 72.1 & 727.533 .702 \\
\hline Februari & 0 & 0 & 0 \\
\hline Maret & 20 & 72.1 & 746.286 .191 \\
\hline April & 20 & 72.1 & 752.804 .752 \\
\hline Mei & 10 & 36.05 & 374.883 .229 \\
\hline Juni & 6.98 & 25.163 & 259.758 .881 \\
\hline Juli & 20 & 72.1 & 753.719 .701 \\
\hline Agustus & 20 & 72.1 & 760.814 .341 \\
\hline September & 18 & 64.89 & 694.918 .690 \\
\hline Oktober & 30 & 108.15 & 1.172 .329 .778 \\
\hline November & 30.427 & 109.689 & 1.198 .347 .210 \\
\hline Desember & 30 & 108.15 & 1.119 .715 .884 \\
\hline Total & 225.407 & 812.592 & 8.561.112.359 \\
\hline Rata- rata/bulan & 20.492 & & \\
\hline
\end{tabular}

Tabel 4. Persediaan akhir bahan baku ADC-12 tahun 2018

\begin{tabular}{|c|c|c|c|c|c|}
\hline Bulan & $\begin{array}{c}\text { Persedian awal } \\
(\mathrm{Kg})\end{array}$ & Pembelian (Kg) & $\begin{array}{c}\text { Total Persedian awal } \\
(\mathbf{k g})\end{array}$ & Pemakaian (kg) & $\begin{array}{c}\text { Persedian akhir } \\
(\mathrm{kg})\end{array}$ \\
\hline Jan & 47.867 & 20.000 & 67.867 & 35.000 & 32.867 \\
\hline Feb & 43.806 & 0 & 43.806 & 25.000 & 18.806 \\
\hline Mar & 22.993 & 20.000 & 42.993 & 27.000 & 15.993 \\
\hline Apr & 24.395 & 20.000 & 44.395 & 24.000 & 20.395 \\
\hline Mei & 20.395 & 10.000 & 30.395 & 19.000 & 11.395 \\
\hline Jun & 13.175 & 6.980 & 20.155 & 18.000 & 2.155 \\
\hline Jul & 2.155 & 20.000 & 22.155 & 18.000 & 4.155 \\
\hline Ags & 4.155 & 20.000 & 24.155 & 19.000 & 5.155 \\
\hline Sep & 22.745 & 18.000 & 40.745 & 28.000 & 12.745 \\
\hline Okt & 6.977 & 30.000 & 36.977 & 28.000 & 8.977 \\
\hline Nov & 5.076 & 30.427 & 35.503 & 11.737 & 23.766 \\
\hline Des & 23.766 & 30.000 & 53.766 & 37.000 & 16.766 \\
\hline Total & 237.505 & 225.407 & 462.912 & 289.737 & 173.175 \\
\hline Rata2/bulan & 19.792 & 18.784 & 38.576 & 24.145 & 14.431 \\
\hline Rata2/hari & & & & 929 & \\
\hline
\end{tabular}


Berdasarkan Tabel 4 dapat dilihat bahwa total persediaan awal bahan baku ADC-12 yang paling tinggi di bulan Januari sebesar $67.867 \mathrm{~kg}$ dengan total nilai keseluruhan di tahun 2018 sebesar $462.912 \mathrm{~kg}$. Nilai dari total persediaan awal bahan baku merupakan hasil dari penjumlahan persediaan awal dan pembelian bahan baku. Sedangkan total persedian akhir ADC-12 di tahun 2018 sebesar $173.175 \mathrm{~kg}$. Nilai dari persediaan akhir didapat dari hasil pengurangan antara total persediaan bahan baku perperiode dikurang nilai dari pemakaian. Hasil pengurangan antara total persediaan bahan baku perperiode dikurang nilai dari pemakaian.

Data pembelian dan pemakaian aktual bahan baku dapat mendukung penyajian data kuantitas pesanan dan tingkat persediaan rata-rata. Persediaan awal bahan baku ADC-12 di tahun 2018 sebesar $47.867 \mathrm{~kg}$. Data kuantitas pesanan dan tingkat persediaan rata- rata dapat dilihat padatabel dibawah ini.

Tabel 5. Kuantitas pesanan dan tingkat persediaan rata- rata perusahaan

\begin{tabular}{|c|c|c|c|c|c|c|}
\hline Bulan & $\begin{array}{l}\text { Persedian awal } \\
(\mathrm{Kg})\end{array}$ & Pembelian (Kg) & $\begin{array}{c}\text { Total Persedian } \\
\text { awal (kg) }\end{array}$ & $\begin{array}{c}\text { Pemakaian } \\
(\mathrm{kg})\end{array}$ & $\begin{array}{c}\text { Balance } \\
\quad(\mathbf{k g})\end{array}$ & Rata-rata (kg) \\
\hline Jan & 47.867 & 20.000 & 67.867 & 35.000 & 32.867 & 50.367 \\
\hline Feb & 43.806 & 0 & 43.806 & 25.000 & 18.806 & 31.306 \\
\hline Mar & 22.993 & 20.000 & 42.993 & 27.000 & 15.993 & 29.493 \\
\hline Apr & 24.395 & 20.000 & 44.395 & 24.000 & 20.395 & 32.395 \\
\hline Mei & 20.395 & 10.000 & 30.395 & 19.000 & 11.395 & 20.895 \\
\hline Jun & 13.175 & 6.980 & 20.155 & 18.000 & 2.155 & 11.155 \\
\hline Jul & 2.155 & 20.000 & 22.155 & 18.000 & 4.155 & 13.155 \\
\hline Ags & 4.155 & 20.000 & 24.155 & 19.000 & 5.155 & 14.655 \\
\hline Sep & 22.745 & 18.000 & 40.745 & 28.000 & 12.745 & 26.745 \\
\hline Okt & 6.977 & 30.000 & 36.977 & 28.000 & 8.977 & 22.977 \\
\hline Nov & 5.076 & 30.427 & 35.503 & 11.737 & 23.766 & 29.635 \\
\hline Des & 23.766 & 30.000 & 53.766 & 37.000 & 16.766 & 35.266 \\
\hline Tot & 237.505 & 225.407 & 462.912 & 289.737 & 173.175 & 318.044 \\
\hline Rata2/hari & & & & 929 & & \\
\hline
\end{tabular}

Berdasarkan Tabel 5 dapat dilihat bahwa total tingkat persediaan rata - rata bahan baku ADC-12 tahun 2018 sebesar $318.044 \mathrm{~kg}$. Nilai rata - rata tingkat persediaan bahan baku didapat dari total penjumlahan antara nilai rata - rata tota persediaan awal bahan baku dengan nilai rata - rata persedian akhir kemudian dibagi dua. Agar persediaan bahan baku ADC-12 dapat memenuhi kebutuhan produksi perusahaan harus mampu menanggung beban biaya atas bahan baku yang diperlukan, meliputi biaya pemesanan dan biaya penyimpanan.

\section{Biaya pemesanan}

Biaya pemesanan bahan baku ADC-12 pada periode Januari 2018 sampai dengan Desember 2018 meliputi, biaya batam handling (sewa container, forklift dll), biaya dokumen impor, dan biaya karyawan yang terdiri dari 2 orang. Biaya pemesanan dapat dilihat pada Tabel 6.

Tabel 6 Biaya pemesanan ADC-12 tahun 2018

\begin{tabular}{clr}
\hline No & \multicolumn{1}{c}{ Biaya } & Rincian \\
\hline 1 & Handling fee (SIN-Batam) Rp9.000.000 x frekuensi pembelian sebanyak 11 kali & Rp99.000.000 \\
2 & Dokumen Impor Rp 250.000 x frekuensi pembelian sebanyak 11 kali & Rp8.250.000 \\
3 & Karyawan 1 orang x gaji Rp4.850.000 selama 12 bulan & Rp58.200.000 \\
& & Total
\end{tabular}

Berdasarkan data yang diperoleh dari hasil penelitian, total biaya pemesanan bahan baku ADC-12 tahun 2018 yaitu senilai Rp165.450.000 dengan frekuensi pemesanan yang dilakukan oleh perusahaan yaitu sebanyak 11 kali. Sehingga dapat diperoleh nilai biaya pesan ADC-12 setiap kali pesan yaitu:

Biaya pemesanan setiap kali pesan

$$
\mathrm{S}=\frac{\text { Total biaya pesan }}{\text { Frekuensi pesanan }}
$$

$\mathrm{S}=\frac{R p 165.45000}{11}$

Biaya pemesanan setiap kali pesan $(\mathrm{S})=$ Rp15.040.909 Maka didapat biaya pemesanan ADC-12 setiap kali pesan yaitu senilai Rp15.040.909.

\section{Biaya penyimpanan}

Biaya penyimpanan meliputi, biaya sewa gedung, perawatan gedung, pemakaian listrik dan biaya yang dikeluarkan untuk gaji karyawan.Biaya penyimpanan dapat dilihat pada tabel dibawah ini. 
Tabel 7. Biaya penyimpanan ADC-12 tahun 2018

\begin{tabular}{|c|c|c|}
\hline No & Biaya & Rincian \\
\hline 1 & Sewa gedung & Rp250.000.000 \\
\hline 2 & Perawatan gedung & Rp30.000.000 \\
\hline 3 & Pemakaian Listrik & Rp15.000.000 \\
\hline 4 & $\begin{array}{c}\text { Karyawan } 2 \text { orang x gaji masing - masing per karyawan Rp3.800.000 selama } 12 \text { bulan } \\
\text { Total }\end{array}$ & $\begin{array}{r}\text { Rp91.200.000 } \\
\text { Rp386.200.000 }\end{array}$ \\
\hline
\end{tabular}

Berdasarkan data yang diperoleh, total biaya penyimpanan bahan baku ADC-12 tahun 2018 yaitu sebesar Rp386.200.000 dengan total pemakaian bahan baku sebanyak $289.737 \mathrm{~kg}$. Sehingga dapat diperoleh nilai biaya simpan $\mathrm{ADC}-12$ per kg yaitu:

Biaya simpan per kilogram $(\mathrm{H})$

$$
\begin{aligned}
& \mathrm{H}=\frac{\text { Total biaya simpan }}{\text { total bahan baku terpakaj }} \\
& \mathrm{H}=\frac{R p 386.200 .000}{289.737 \mathrm{~kg}}
\end{aligned}
$$

Biaya simpan per kilogram $(\mathrm{H})=1.332,9$ dibulatkan menjadi 1.333 Maka, nilai dari biaya simpan bahan baku ADC-12 per kilogramnya yaitu sebesar Rp1.333 per kg.

Perhitungan persediaan bahan baku ADC-12 dengan metode Economic Order Quantity (EOQ) Perhitungan persediaan bahan baku ADC-12 dengan metode EOQ membutuhkan data jumlah kebutuhan baku, biaya pemesanan satu kali pesan serta biaya penyimpanan. Data tersebut diformulasikan sebagai berikut:

$$
\begin{aligned}
& \text { Pembelian bahan baku ADC-12 yang ekonomis } \\
& E O Q=\frac{\sqrt{2 \mathrm{DS}}}{\mathrm{H}}
\end{aligned}
$$$$
\text { - Biaya pemesanan satu kali pesan }(\mathrm{S})=\mathrm{Rp} 15.040 .909
$$$$
\text { - Biaya simpan per kilogram }(\mathrm{H})=\mathrm{Rp} 1.333
$$$$
E O Q=\frac{\sqrt{2(289.737 \mathrm{~kg})(\mathrm{Rp} 15.040 .909)}}{\operatorname{Rp} 1.333}
$$$$
E O Q \sqrt{.538 .496 .400}
$$

$\mathrm{EOQ}=80.860,9$ kilogram dibulatkan menjadi $80.861 \mathrm{~kg}$ Maka, didapatkan nilai pembelian bahan baku ADC-12 yang ekonomis dengan menggunakan metode EOQ yaitu sebesar $80.861 \mathrm{~kg}$.

\section{Perhitungan persediaan pengaman (safety stock)}

Persediaan pengaman (safety stock) sangat diperlukan oleh perusahaan untuk menghindari masalah stock out maupun keterlambatan datang atas bahan baku yang diperlukan saat proses produksi berlangsung. Untuk menghilangkan kerugian yang ditimbulkan oleh stock out perusahaan membuat stok pengaman.Dalam melakukan perhitungan persediaan pengaman tentu harus perlu diperhatikan biaya penyimpanan.Penentuan jumlah persediaan pengaman dapat dilakukan melalui perkalian antara standar deviasi dengan standar penyimpangan. Sesuai data - data yang telah diperoleh dapat disimpulkan bahwa Perusahaan menyediakan persediaan bahan baku sebesar $65 \%$ dan kuantitas pengaman sebesar $35 \%$, sehingga nilai deviasi sebesar 0,39 (berdasarkan tabel Z).

Total kebutuhan bahan baku $(\mathrm{D})=289.737 \mathrm{~kg}$

Tabel 8. Perhitungan Standar Deviasi

\begin{tabular}{cccccc}
\hline No & Bulan & Pemakaian $(\mathrm{X})$ & Perkiraan $(\mathrm{Y})$ & Deviasi $(\mathrm{X}-\mathrm{Y})$ & Kuadrat $^{(\mathrm{X}-\mathrm{Y})^{2}}$ \\
\hline 1 & Jan & 35.000 & 24.000 & 11.000 & 121.000 .000 \\
2 & Feb & 25.000 & 24.000 & 1.000 & 1.000 .000 \\
3 & Mar & 27.000 & 24.000 & 3.0000 & 0.000 .000 \\
4 & Apr & 24.000 & 24.000 & 0 & 0 \\
5 & Mei & 19.000 & 24.000 & -5.000 & 25.000 .000 \\
6 & Jun & 18.000 & 24.000 & -6.000 & 36.000 .000 \\
7 & Jul & 18.000 & 24.000 & -6.000 & 36.000 .000 \\
8 & Agt & 19.000 & 24.000 & -5.000 & 25.000 .000 \\
9 & Sep & 28.000 & 24.000 & 4.000 & 16.000 .000 \\
10 & Okt & 28.000 & 24.000 & 4.000 & 16.000 .000 \\
11 & Nov & 11.737 & 24.000 & -12.263 & 150.381 .169 \\
12 & Des & 37.000 & 24.000 & 13.000 & 169.000 .000 \\
& Jumlah & 289.737 & & & 604.381 .169 \\
\hline
\end{tabular}

Perhitungan standar deviasi (SD) sebagai berikut:

$S D=\sqrt{\frac{\sum(x-y)^{2}}{n}}$

$$
\begin{aligned}
& S D=\sqrt{\frac{604.381 .169}{12}} \\
& S D=\sqrt{50.365 .097 .41}
\end{aligned}
$$


$\mathrm{SD}=7.096,83 \mathrm{~kg}$ dibulatkan menjadi $7.097 \mathrm{~kg}$.

Setelah didapatkan nilai standar deviasi, maka dapat dilakukan perhitungan persediaan pengaman dengan rumus berikut

Safety Stock $=$ SD x Z

Safety Stock $=7.097 \times 0,39$

Safety Stock $=2.767,83 \mathrm{~kg}$, dibulatkan menjadi $2.768 \mathrm{~kg}$

Berdasarkan perhitungan di atas, didapatkan nilai persediaan pengaman (safety stock) untuk bahan baku ADC-12 yaitu sebesar $2.768 \mathrm{~kg}$ dengan standar deviasi sebesar $7.097 \mathrm{~kg}$ dan standar penyimpangan sebesar 0,39. Data ini dapat dilihat pada Tabel 9.

Tabel 9. Safety stock bahan baku ADC-12 periode 2018

\begin{tabular}{cccc}
\hline Tahun & Standar Deviasi & Standar Penyimpangan & Safety Stock \\
\hline 2018 & $7.097 \mathrm{~kg}$ & 0,39 & $2.768 \mathrm{~kg}$ \\
\hline
\end{tabular}

\section{Perhitungan reorder point (ROP)}

Reorder point (ROP) atau pemesanan kembali merupakan kegiatan yang akan dilakukan oleh perusahaan saat kebutuhan bahan baku dibutuhkan kembali untuk proses produksi. Perhitungan ROP sangat penting dilakukan, karena dalam proses pemesanan barang terdapat waktu tunggu (lead time) yaitu suatu kondisi dimana barang yang akan dipesan tidak bisa langsung tersedia dan dapat digunakan. ROP dihitung berdasarkan perkalian antara lead time dengan kebutuhan barang dalam waktu tertentu. Waktu tunggu yang terdapat pada Perusahaan yaitu 14 hari (2 minggu).Sehingga nilai ROP dapat ditentukan sebagai berikut.

Tabel 10. Reorder point bahan baku ADC-12 tahun 2018

\begin{tabular}{cccccc}
\hline Tahun & Lead time (hari) & Rata-rata pemakaian per hari $(\mathrm{kg})$ & $\mathrm{dL}$ & $\mathrm{SS}$ & $\mathrm{ROP}$ dL+SS (kg) \\
\hline 2018 & 14 & 929 & 13.006 & 2.768 & 15.774 \\
\hline
\end{tabular}

Berdasarkan Tabel 10 didapatkan nilai pemesanan kembali bahan baku ADC-12 sebesar 15.774 kg dengan waktu tunggu selama 14 hari.

\section{Perhitungan persediaan maksimum (maximum inventory)}

Perhitungan maximum inventory menggunakan rumus berikut.

Maximum Inventory $=$ Safety Stock + EOQ

Nilai safet stock $=2.768 \mathrm{~kg}$

Nilai EOQ $=80.861 \mathrm{~kg}$

Maximum Inventory $=2.768 \mathrm{~kg}+80.861 \mathrm{~kg}$

Maximum Inventory $=83.629 \mathrm{~kg}$

Berdasarkan hasil perhitungan, batas jumlah persediaan yang dapat diandalkan yaitu sebesar 83.629 $\mathrm{kg}$.

\section{SIMPULAN}

Berdasarkan hasil dan pembahasan penelitian, dapat diambil simpulan sebagai berikut:

1. Perhitungan kuantitas persediaan bahan baku ADC-12 dengan menggunakan

2. Kuantitas persediaan pengaman (safety stock) yang dibutuhkan perusahaan sebelum dilakukan pemesanan kembali yaitu sebanyak $2.768 \mathrm{~kg}$.

3. Nilai reorder point yang dibutuhkan perusahaan untuk memesan kembali bahan baku yang dibutuhkan sebelum mengalami stock out sebesar $14.038 \mathrm{~kg}$ dengan waktu tunggu (lead time) selama 14 hari.

\section{DAFTAR PUSTAKA}

Amrillah, A., \&Wi Endang NP, M. (2016). Analisis Metode Economi Order Quantity (EOQ) Sebagai Dasar Pengendalian Persediaan Bahan Baku Pembantu (Studi Pada PG. Ngadirejo Kediri - PT.
Perkebunan Nusantara X). Jurnal Administrasi Bisnis S1 Universitas Brawijaya, 33(1), 35-42.

Björk, K.-M. (2012). The Fuzzy Economic Order Quantity Problem with a Finite Production Rate and Backorders. Applied Computational Intelligence and Soft Computing, 2012, 18.Bahan Baku Dengan Menggunakan Metode Economic Order Quantity (EOQ) Pada Perusahaan Roti Bonansa. Management Analysis, 5(4), 10.

Fauzi, R. A., \& Hartono, R. (2019). Analisis Pengendalian Persediaan Benang Pada Produk Underwear Dengan Metode EOQ (Studi Kasus pada PT. Indonesia Wacoal). Jurnal Ilmiah Binaniaga, 14(1), 1.

Han, E., Fajrin, A., \& Slamet, A. (2016). Analisis Pengendalian Persediaan Bahan Baku Dengan Menggunakan Metode Economic Order Quantiti ( EOQ ), 5(4), 289-298.

Indah, D. rosa, \& Maulida, Z. (2018). Pengendalian Persediaan Bahan Baku Pada PT. Aceh Rubber Industries Kabupaten Aceh Tamiang. Jurnal Manajemen Dan Keuangan, 7(2), 157.

Lahu, E. P., \& Sumarauw, J. S. .(2017). Analisis Pengendalian Bahan Baku Guna Meminimalkan Biaya Persediaan Pada Dunkin Donuts Manado. Jurnal EMBA, 5(3), 4175-4184.

Palupi, P. M., Korawijayanti, L., \& Handoyono, R. (2018). Penerapan Metode Economic Order Quantity (EOQ) Untuk Meningkatkan Efisiensi Biaya Persediaan Bahan Baku ( Studi Kasus pada PT Nusamulti Centralestari ). Prosiding Seminar Nasional Unimus, 1, 426-435.

Sofiyanurriyanti, S. (2017).Analisa Persediaan Bahan Baku Mengunakan Metode EOQ (Economy Order 
Quantity) di CV. Alfa Nafis. Jurnal Ilmiah Rekayasa, 65 10(2),

Sulaiman, F., \& Nanda.(2015). Pengendalian Persediaan Bahan Baku Dengan Menggunakan Metode EOQ Pada UD. Adi Mabel. Jurnal Teknovasi, 02(1), 111.

Turnip, M. S. K., \& Kartikasari, D. (2017). Analisis Perbandingan Pengendalian Persediaan Bahan Baku Methanol Antara Pendekatan Model Economic Order Quantity Dengan Just in Time Pada Cv Mamabros Servicindo Batam. Journal of Applied Managerial Accounting, 1(2), 77-90.

Unsulangi, H. I., Hassan Jan, A., \& Tumewu, F. (2019).Analisis Economic Order Quantity (Eoq) Pengendalian Persediaan Bahan Baku Kopi Pada Pt. Fortuna Inti Alam. Jurnal EMBA, 7(1), 51-60. 